\title{
Mary Kelly
}

"Let's Draw!" was the greeting heard all over the state of Wisconsin as classrooms of boys and girls tuned in to weekly broadcasts of the creative art education radio program transmitted by the Wisconsin School of the Air station, WHA, during the 34 year period from 1936 to 1970. "Let's Draw" is also the title of that radio series and the topic of a Ph.D. dissertation currently in progress.

At WHA, "Let's Draw" was the fourth art education series to be aired. The woman who was the Art Supervisor of the Madison Public Schools, Irene Buck, first conducted a "Picture Study" radio program in the 1931-32 school year, and later that year a series called "Art Craft" began with Frank Zozzora from the University of Wisconsin Art Education Department giving four talks on men of art. In the fall of 1932, that series was taken over by Wayne Claxton of the same department and by the following year the name of that series was changed to "Creative Art". The program was offered only 3 of the 4 years that spanned the 1932-1936 period. The "Creative Art" program had evolved from one which first placed greatest emphasis upon the more formal, technical and manipulative side of art; it gradually became one that focused primarily on the expression of ideas and impusles of the student. In 1936, Claxton left Wisconsin and James A. Schwalbach was hired to take over the radio programming in Art Education.

Schwalbach had some experience as a high school student writing, producing and narrating his own educational radio programs on safety, and he was an art teacher with several years of teaching experience by the time he applied for the job at station WHA. When Harold B. McCarty, the Director, asked Jim to give him some suggestions for a program or two, he came back with an outline for the entire year. This enthusiasm was the hallmark of the way in which Jim Schwalbach embraced the entire 34 years of involvement with the "Let's Draw" project. Surely this spirit carried over the airways to the students and teachers who began using the early broadcasts in spite of the technical difficulties experienced in the early days of the radio medium.

The "Let's Draw" series was aimed at fifth through eighth grade students but it was often adapted to teach creative art at levels from first through eighth grade. The series was first designed to be used in schools where no other creative visul art instruction was given; the "Let's Draw" series was initially meant to serve as an introduction to the artistic method while stimulating the imagination of the young participants. The later scripts were written for use by the art specialists more as a point of departure that should be expanded by student and teacher exchanges. Paramount to the "Let's Draw" project was the goal to allow students freedom to express their own ideas and to help students develop individuality. "We do not copy," and, "Art is fun," were phrases common throughout the series. Each of the segments was a mix of music and dialog or narration. Many of the programs involved less familiar children's stories and some had their basis in the folklore of Wisconsin communities. 
The first broadcasts were intended to be easily used by the classroom teacher who, in those days, was often a high school graduate who may have received a teacher's certificate for one or two years of normal school training before entering the field of teaching. Most of them were in multi-level classrooms often set in one or two room school buildings. Thirty years later the program was geared more to use by the teacher with a four year diploma who had specialized art training and could augment the concepts covered in the broadcast. Over the decades the programming evolved to meet the changing needs of the teachers and students alike. A portion of the series, after 1963 , was designed to employ "Radiovision", the technology which used specifically created film strips with the radio programs.

One of the ways Professor Schwalbach kept in touch with the needs of his listeners was by going into the schools unannounced, sitting in the back of classrooms, observing the students as they participated in the programs. He also encouraged teachers to periodically send in the art works that students created. Not only did this practice serve to evaluate how the students were able to relate to the programming but it gave him, and his staff, an opportunity to select some students to receive recognition in the form of post cards of "Honorable Mention". Some children's art works were also chosen to become part of traveling exhibits that went back to the participating schools while other exemplary art projects were chosen to be used to illustrate the teacher's manual to be sent out in the coming year. A few students were chosen to become part of a "Gathering of the Clan" program held each spring in WHA's Radio Hall. The students and adults would come to Madison from all over Wisconsin to take part in that broadcast. In later years lay advisory boards also were selected to help appraise the direction "Let's Draw" should take in the future.

Awards for the "Let's Draw" series spanned the life of the program. In 1937 the segment entitled "Mystic King of the North" was entered in the First American Exhibition of Recordings of Educational Radio Programs conducted at Ohio State University in Columbus, Ohio. It received the highest honor then and subsequent entries "The Wild Ride of Ichabod Crane" in 1945 and "The Lights of Christmas" in 1964 did equally as well.

There is no accurate way to determine the actual number of listeners to any given broadcast or the impact it has had. We are, however, able to trace the growth of the series in the number of requests made to the radio station for the manuals (that were designed to be used in conjunction with the broadcasts) and by the amount of art work that was received. Those records indicate that an audience of 120,000 classrooms was participating by the later part of the 1950 's. Little is known about the student populations using the programs other than grade levels. It is presumed that the children were in heterogeneously grouped classrooms, located within the state of Wisconsin. This study does not attempt to evaluate the series in terms of biases or role stereotyping that may have existed in some of the presentations or the literature chosen for use within certain programs.

Evidence of this long standing educational art program is widely scattered now that fifteen years have lapsed since the final broadcast. Some of the texts that are part of this investigation came from personal interviews with 
the late, James A. Schwalbach, who wrote and was the narrator of many of the broadcasts of "Let's Draw" and with Harold B. McCarty, who was the WHA station director for 40 years.

Philip J. Grise and others conducted a review of the literature on educational radio at Florida State University of Tallahassee at the Center for Educational Technology in 1974. Two of their conclusions were:

"Other areas of need are those of longitudinal studies concerning the effects of radio used over an extended period of time, and studies of single-session attention span of students."

"Most of the history of radio research reflects little emphasis on maximizing a radio broadcast's impact. There is a need for careful study of what factors make some instructional radio programs effective, others mildly effective, and some outstanding."

A survey of the literature on the educational effectiveness of radio is very sparce. Literature on the use of radio for art instructional purposes is virtually non-existent. A major effort in using radio for art education is the pioneer effort of James A. Schwalbach in his "Let's Draw" program that was broadcast by station WHA as one of the Wisconsin School of the Air programs which were broadcast from 1936 to 1970.

The "Let's Draw" series appears to have made a significant contribution, not only to the education of Wisconsin students, but also to the importance of radio as an instructional approach to art education. It provides a longitudinal view of the effects of radio used over an extended period of time and an opportunity to study what factors made this radio program outstanding. Unfortunately, a thorough, systematic account of this program has never been written. Furthermore, there has been no educational analysis of the reasons for its apparent effectiveness.

The purpose of this research is:

(1) To describe the program

(2) Outline its chronology of development

(3) Examine the historical context in which it was developed and used, and

(4) Attempt to suggest some reasons for its apparent effectiveness.

By 1965 , one or more visual art specialists had been hired to serve the needs of the students in 75

1955 , the school districts employing art teachers was a mere $25 \%$. It seems obvious that there had been a general recognition of the need for art education in public schools in Wisconsin that was perhaps due to the effectiveness of "Let's Draw".

Today, under most circumstances, it would not be recommended that 
mass media be the primary means for instructing students in the visual arts. It is believed by some, however, that young people today do not have enough opportunities for productive self-expression, and there is a continuous effort in most educational settings to curb spending. A review of the thirty-four year "Let's Draw" series provides a valid record of a long-term experiment which tested the hyphothesis: "Can aesthetics education be successfully taught through an aural medium". As such, it will provide an important background for the development of supplemental, individually guided art education programs which could utilize modern technology in the form of cassette players, tapes and an assortment of art materials. Applications for the programs could be in addition to ongoing art curricula or as alternative studies for those who cannot participate in other programs at a given time.

Individuals who have information and details of this or other radio broadcasts in art education are encouraged to send it to this writer: Mary F. Kelly, P.O. Box 146, Cottage Grove, WI 53527.

\section{REFERENCES}

Claxton, W. An Experiment in Radio Art Education. Master's thesis, University of Wisconsin 1936.

Grise, P. J. Jr., Epstein, K. I., and Lukin, T. G. Educational Radio: A Review of the Literature. Florida State University, Tallahassee, Center for Educational Technology. 1974.

Schwalbach, J. A. An Experiment in the Teaching of Art Over The Wisconsin School of the Air. Master's thesis, University of Wisconsin 1938. 